Article

\title{
Review and Development of a Land Consumption Evaluation Method Based on the Time-Area Concept of Last Mile Delivery Using Real Delivery Trip Data
}

\author{
Maren Schnieder * (D), Chris Hinde and Andrew West \\ The Wolfson School of Mechanical, Electrical and Manufacturing Engineering, Loughborough University, \\ Loughborough LE11 3TU, UK; c.j.hinde@lboro.ac.uk (C.H.); a.a.west@lboro.ac.uk (A.W.) \\ * Correspondence: m.schnieder@lboro.ac.uk
}

Received: 11 November 2020; Accepted: 15 December 2020; Published: 19 December 2020

\begin{abstract}
The paper proposes an evaluation method providing decision support for policymakers in regard to the land consumption of transport activities. Due to the increasing pressure on vehicle parking, traffic jams and the housing crisis in large cities, it is important to use road space effectively. The primary objective of this paper is to review and evaluate the published research about the time-area concept, as well as proposing an evaluation method for the time-area requirements of vehicles used in last mile delivery such as pedestrian porters, bicycles, cargo bikes, sidewalk autonomous delivery robots (SADRs) and delivery vans. The time-area concept measures the size of an area occupied during a transport activity and the duration for which it is occupied for standing, as well as moving transport units. While most of the research applies the time-area concept to compare various modes of transport used to move people around a city, this paper focusses on moving parcels and evaluates the effect that operating strategies and policy changes have on the time-area requirements of a single mode of transport. The study builds on a real trip data set of parcel deliveries in London.
\end{abstract}

Keywords: time-area concept; last mile delivery; land consumption; land-use planning; land-use efficiency

\section{Introduction}

Reducing land consumption [1], as well as increasing land use efficiency [2], is a key objective for policymakers. Due to increasing congestion, parking pressure and housing shortages in cities, it is important to use space effectively and to keep the space requirements of transport activities to a minimum. Every square metre devoted to streets and parking locations is lost for housing and parks. Traditional measures used to evaluate traffic, such as vehicle kilometre travelled (VKT), traffic volume, or the number of parking spots, cannot be used to assess the area requirements, given that vehicles have different sizes and velocities. For example, traveling by car requires more space than by bicycle. However, a car travels quicker. Thus, the area is occupied for a shorter time. The time-area concept is used to quantify the "ground area consumed for movement and storage of vehicles, as well as the amount of time for which the area is consumed." Bruun [3]. In simple terms, the instantaneously required area is multiplied by the duration for which it is occupied. The concept of combining time and area can be readily applied to comparing parking requirements; for example, five cars parked over one hour requires the same time-area as one car over $5 \mathrm{~h}$.

The time-area concept combines the space requirements for moving and parking into one metric and can be used to compare multiple ground-based modes of transport with different velocities and sizes. As shown in Figure 1, a pedestrian could travel for $1 \mathrm{~h}$ and require a space of $2 \mathrm{~m}^{2}$ during this time. A cyclist might require $6 \mathrm{~m}^{2}$ for the safe operation of the bicycle, but can typically travel the 
same distance in a quarter of the time. Thus, the time-area requirement of the cyclist is $1.5 \mathrm{~m}^{2} \times \mathrm{h}$. However, the cyclist must store the bicycle after the trip, and $30 \mathrm{~min}$ storage of the bicycle adds another $0.5 \mathrm{~m}^{2} \times \mathrm{h}$ to the time-area requirement.

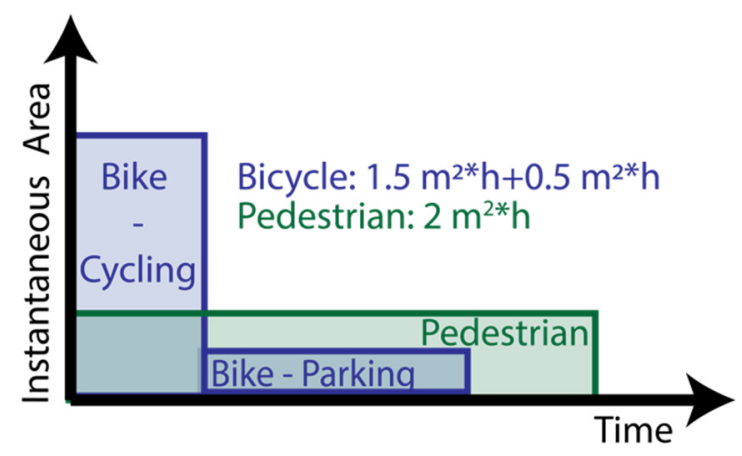

Figure 1. Time-area requirements of a bicycle (blue) and a pedestrian (green).

The time-area concept is relevant for policymakers in macro-economic decision making to allocate a limited resource (i.e., space) to maximise welfare [3], which is crucial for sustainable development. Decreasing the land required for streets frees up space for other purposes in cities (e.g., housing and parks) and reduces the fragmentation of habitats and ecosystems in rural areas. Land consumption should not be seen on its own but instead as an interaction between economics, demographics and transport [4]. Thus, easy to use tools and evaluation methods are needed to allow policymakers to optimise land use [4]. The time-area concept also calculates the opportunity cost of modes of transport that compete for space on the road and within cities.

Bruun [3] concluded in his doctoral thesis in 1992 that all publications and presentations or interviews and unpublished papers limit their time-area assessment to a single trip with multiple modes of transport, assumed velocity and occupancy rates. Most studies neither vary the storage duration nor travelled distance. Due to their anecdotal character, he advises against using these studies to draw conclusions for policymaking.

Until now, the time-area concept has only been mentioned in a few journal publications. While some of the publications propose equations to calculate the time-area requirements, all papers apart from Schnieder et al. [5] calculate the time-area requirements for a few exemplary trips under constraints. Schnieder et al. [5] applied the time-area concept to a simulation of last mile delivery but only used average instantaneous area requirements, which ignores the fact that the time-area requirements change depending on the traffic flow and speed. This paper addresses this gap by integrating the time-area concept into the evaluation of a cyber-physical system of last mile delivery for macro-economic decision making. The evaluation method is developed for vehicles used in last-mile delivery, such as Sidewalk Autonomous Delivery Robots (SADRs), pedestrians, pedestrians with a bag, bicycles, cargo bikes, various vans and trucks. The paper differs in three aspects from previous research: (1) Instead of simply comparing a few exemplary trips, as other authors have done so far, this paper calculates the time-area requirements for a real delivery trip dataset over one year, including variations in, e.g., traffic flow and number of parcels per day, due to seasons and weekdays. (2) This paper, such as that of Schnieder et al. [5], applies the time-area concept to last mile delivery and not, as other authors, to people moving around the city. (3) The papers usually compare various modes of transport, whereas this paper evaluates the effect that policies and operating strategies have on the time-area requirements of a single mode of transport.

Firstly, the paper reviews the published literature about the time-area concept and lists the equations and methods to calculate the time-area requirements. Secondly, two definitions of the time-area requirements are evaluated. Thirdly, the specifications of the evaluation method are illustrated. Finally, the evaluation method is applied to a last mile delivery trip dataset and various policies and operating strategies are simulated and assessed. 


\section{Literature}

Two time-area formulations have been proposed in the literature: discrete formulation (i.e., required space for safe operation) and continuous flow formulation (i.e., share of the provided infrastructure) (Figure 2). The first is based on a buffer area around the vehicle (e.g., $2 \mathrm{~s}$ following rule) and the latter is based on the flow of transport units passing through an area.

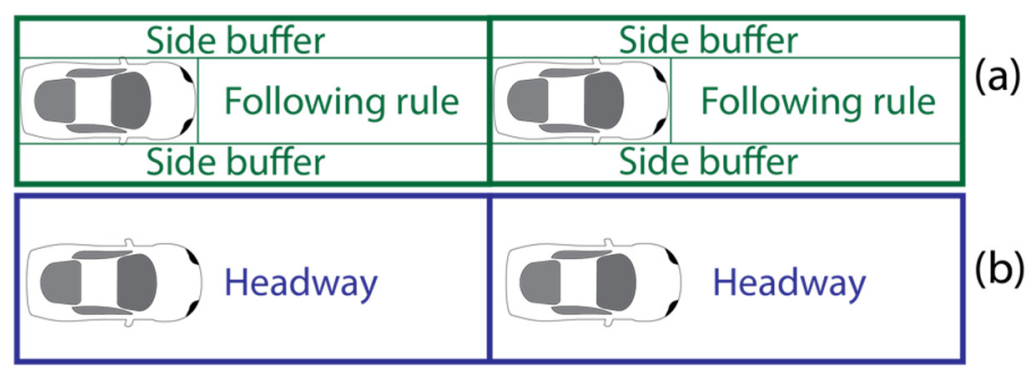

Figure 2. Time-area formulation (a) discrete and (b) continuous flow.

The following literature review only considers studies published in the last 30 years to ensure that the studies consider the same vehicles, traffic flows, and traffic law. For a review of the papers published in the 1960s, 1970s, and 1980s, see Bruun [3].

\subsection{Discrete Formulation}

Bruun [3] proposed the following equation to calculate the time-area requirements:

$$
T A_{i}=T A_{i}^{1}+T A_{i}^{2}+T A_{i}^{3}=\int_{0}^{T_{1}} W * L_{i}\left(v_{i}\right)_{1} d t+\int_{T_{1}}^{T_{2}} W * L_{i}\left(v_{i}\right)_{2} d t+\int_{T_{2}}^{T_{3}} W * L_{i}\left(v_{i}\right)_{3} d t
$$

where

$T A_{i} \quad$ Time-area requirements for vehicle $\mathrm{i}$;

$T A_{i}^{1} \quad$ Time-area requirements for vehicle $\mathrm{i}$ when entering the area;

$T A_{i}^{2} \quad$ Time-area requirements for vehicle $i$ when being within the area;

$T A_{i}^{3} \quad$ Time-area requirements for vehicle $\mathrm{i}$ when leaving the area;

$W \quad$ Width of the vehicle;

$L_{i}\left(v_{i}\right)_{1}$ Module length (front safety buffer plus vehicle length) when vehicle is entering the area;

$L_{i}\left(v_{i}\right)_{2}$ Module length (front safety buffer plus vehicle length) when vehicle is within the area;

$L_{i}\left(v_{i}\right)_{3}$ Module length (front safety buffer plus vehicle length) when vehicle is leaving the area;

$T_{1} \quad$ Timepoint when vehicle is fully in the area;

$T_{2} \quad$ Timepoint when vehicle starts to leave the area;

$T_{3} \quad$ Timepoint when vehicle has left the area.

These equations are more complicated than simply multiplying an area by a time because the time-area requirements are calculated per street segment for a vehicle entering, being within and exiting the segment. Usually, the time-area requirements are calculated per trip and not per street segment. The first and the last integrals are not required if the time-area requirements of a complete trip are analysed.

$$
L_{i}\left(v_{i}\right)_{2}=f\left(v_{i}\right)+\delta
$$

where

$L_{i}\left(v_{i}\right)_{2}$ Module length (front safety buffer plus vehicle length) when vehicle is within the area;

$f\left(v_{i}\right) \quad$ Safety buffer in front of vehicle; 
Vehicle length.

Bruun [3] simplified the middle part of the equation as follows:

$$
T A_{i}^{2}=W * \delta\left(T_{2}-T_{1}\right)+W \int_{T_{1}}^{T_{2}} f\left(v_{i}\right) d t
$$

where

$T A_{i}^{2} \quad$ Time-area requirements for vehicle i when being within the area;

$W \quad$ Width of the vehicle;

$f\left(v_{i}\right)$ Safety buffer in front of vehicle;

$\delta \quad$ Vehicle length;

$T_{1} \quad$ Timepoint when vehicle is fully in the area;

$T_{2} \quad$ Timepoint when vehicle is within the area.

Bruun [3] also stated that: "The length of the shadow (front buffer area) is directly a function of the speed and of the regime of safety being used and will change continuously with the speed profile, but it can vary widely between individuals and situations in the case of a manually driven mode. If the speed profile is simple, such as constant speed, an analytic expression can be used. Otherwise, piecewise approximation or even numerical tables can be used to describe this profile." However, since the legally required safe separation distance $f\left(v_{i}\right)$ (nowadays usually the $2 \mathrm{~s}$ following rule) does not depend on the travel time $t$, this factor can be placed outside of the integral:

$$
T A_{i}^{2}=W * \delta\left(T_{2}-T_{1}\right)+W * f\left(v_{i}\right) \int_{T_{1}}^{T_{2}} 1 d t
$$

Then the integral can be solved:

$$
\begin{gathered}
T A_{i}^{2}=W * \delta\left(\mathrm{T}_{2}-T_{1}\right)+W * f\left(v_{i}\right) \int_{T_{1}}^{T_{2}} 1 d t \\
T A_{i}^{2}=W *\left[\delta\left(\mathrm{T}_{2}-\mathrm{T}_{1}\right)+f\left(v_{i}\right) *\left(\mathrm{~T}_{2}-\mathrm{T}_{1}\right)\right] \\
\mathrm{T} A_{i}^{2}=W *\left[\left(\delta+f\left(v_{i}\right)\right) *\left(\mathrm{~T}_{2}-T_{1}\right)\right]
\end{gathered}
$$

Bruun [3] stated that his Equation (3) has to be solved in a piecewise fashion if the velocity is not constant. However, this is not necessary. As explained later, based on Equations (18) and (19), it is possible to calculate the time-area requirements when the velocity is not constant by simply using the average speed, when the following distance is assumed to be the $2 \mathrm{~s}$ following rule.

Bruun et al. [6] utilised the now obsolete "one vehicle length per $10 \mathrm{mph}$ " $(16.1 \mathrm{~km} / \mathrm{h})$ following rule to calculate the instantaneous area requirements (buffer area in front of the vehicles plus vehicle) depending on the velocity. They suggested that the equation is for constant speed in moderate to heavy traffic.

$$
\mathrm{M}=\mathrm{W} * \mathrm{~L}_{\mathrm{i}}\left(\mathrm{v}_{\mathrm{i}}\right)=\mathrm{W} *\left(\delta+\mathrm{B}_{2} \frac{\delta}{16.1} * \mathrm{v}_{\mathrm{i}}\right)
$$

where

M Module length;

W Width of the right-of-way;

$\mathrm{L}_{\mathrm{i}}\left(\mathrm{v}_{\mathrm{i}}\right)$ Length of the vehicle and shadow;

$\delta \quad$ Length of the vehicle;

$\mathrm{B}_{2} \quad$ Factor for unit consistency;

$\mathrm{v}_{\mathrm{i}}$ Velocity. 
While Brunner et al. [7] did not mention the time-area concept, they proposed an equation to calculate the area requirements of transport activities. Whilst the above equations calculate the time-area requirements per vehicle, they calculated the instantaneous area requirements per person:

$$
A_{t_{i}}=\frac{\left(11_{i}+s_{f_{i}}\right) \frac{w}{n_{p_{i}}}}{n_{\text {eff }_{i}}}, i=1,2, \ldots n_{M T}
$$

where

$\mathrm{A}_{\mathrm{t} \_\mathrm{i}} \quad$ Related traffic space demand of vehicle $\mathrm{i}$ in fluent traffic;

$11_{\mathrm{i}} \quad$ Length of vehicle $\mathrm{i}$;

$\mathrm{s}_{\mathrm{f}_{\mathrm{i}}} \quad$ Distance to front vehicle (based on a speed-dependent approach for motorised individual transport);

w Lane width, assumed to be $3 \mathrm{~m}$;

$\mathrm{n}_{\mathrm{p}_{-} \mathrm{i}}$ Possible number of parallel driving vehicles in one lane (cars and busses: 1, Powered two-wheelers: 2, micro-mobility and walking: 3);

$\mathrm{n}_{\text {eff_i }}$ Effective number of persons in vehicle $\mathrm{i}$, based on the space offer and occupancy rate;

$\mathrm{n}_{\mathrm{MT}} \quad$ Number of compared means of transport.

In Brunner et al. [7], the $2 \mathrm{~s}$ rule to determine the distance to the front vehicle is used, except for public transport vehicles, where the length of the vehicle itself is used as the minimum distance.

In sum, the equations proposed for the discrete time-area formulation are relatively similar or can be transformed into one another with minimal changes.

\subsection{Continuous Formulation}

Bruun et al. [6] proposed the following formula for the simple case with uninterrupted, moderate to heavy traffic flow with constant velocity:

$$
\overline{T A}=\frac{W S}{k v}
$$

where

$T$ Time under consideration;

A Analysis area;

$S$ Length of right-of-way;

$W \quad$ Width of the area of right of way;

$k$ Traffic density;

$v$ Velocity.

Shin et al. [8] reported the following time-area equation:

$$
\overline{T A}=\frac{W * D}{\bar{a} * q}
$$

where

$T$ Time;

A Area required;

$W$ Width of right-of-way;

$D$ Travel distance;

$\bar{a} \quad$ Average occupancy of vehicles;

$q \quad$ Flow rate of vehicles in one lane per hour. 
Shin et al.'s [8] and Bruun et al.'s [6] equations are essentially the same and can be transformed from one to the other based on the fundamental stream equation [9]:

$$
q=k v
$$

where

$q \quad$ Flow rate of vehicles in one lane per hour;

$k$ Traffic density;

$v$ Velocity.

\subsection{Parking and Storage}

The time-area requirements of parked vehicles can be estimated by dividing the size of a parking lot by the number of parking spots and multiplying this by the parking duration [6].

$$
\mathrm{TA}_{\mathrm{i}}=\mathrm{A}_{\mathrm{eff}} \mathrm{t}
$$

where

$\mathrm{T}$ Time under consideration;

$\mathrm{A}_{\mathrm{i}} \quad$ Analysis area;

$\mathrm{A}_{\text {eff }}$ Effective area per vehicle (area of parking lot/number of vehicles);

$\mathrm{t}$ Parking time.

Shin et al. [8] did not state how the area $A$ is defined. They seem to include a buffer area around the vehicle plus a share of the manoeuvring space, given that they assumed a smaller instantaneous area requirement per car in a surface parking lot than in a garage facility. Furthermore, they suggested dividing the instantaneous area by the number of floors for multi-story car parks.

$$
\overline{T A}=\frac{A_{s} * T_{S}}{\bar{a}}
$$

where

$T_{S}$ Time stationary;

$A_{s} \quad$ Area required for stationary object;

$\bar{a} \quad$ Average occupancy of vehicle.

Brunner et al. [7] did not specify the type of parking spot. They seemed to refer to a parallel parking spot or on-street parking, as the area is too small to account for the manoeuvring space in parking lots.

$$
A_{p_{-} i}=\frac{\left(11_{i}+l_{p_{i}}\right) *\left(w 1_{i}+2 w_{p_{i}}\right)}{n_{\text {eff_i }}}, i=1,2, \ldots n_{M T}
$$

where

$\mathrm{A}_{\mathrm{p} \_\mathrm{i}} \quad$ Related space demand of vehicle i while parking;

$11_{\mathrm{i}} \quad$ Length of vehicle;

$1_{p_{i}} \quad$ Longitudinal distance to front vehicle (passenger car: $0.9 \mathrm{~m}$, powered two-wheeler: $0.2 \mathrm{~m}$, public transport vehicle: $2 \mathrm{~m}$ );

$\mathrm{w}_{\mathrm{i}} \quad$ Width of vehicle, including exterior parts;

$\mathrm{w}_{\mathrm{p}_{\mathrm{i}}} \quad$ Required additional lateral parking space (passenger car: $0.15 \mathrm{~m}$, powered two-wheeler: $0.25 \mathrm{~m}$, public transport vehicle: $2 \mathrm{~m}$ );

$\mathrm{n}_{\text {eff } \_\mathrm{i}}$ Effective number of persons in vehicle;

$\mathrm{n}_{\mathrm{MT}} \quad$ Number of compared means of transport. 


\subsection{Instantaneous Area Requirements Published in The Literature}

The published instantaneous area requirements [3,6-8] are listed in Table 1, including a report that did not specify the methods/equations used [10]. Parking $\mathrm{m}^{2}$ and moving $\mathrm{m}^{2}$ refers to the instantaneous area requirements of a parking and moving transport unit, respectively. Especially for public transport vehicles, the instantaneous area requirements should be divided by the number of occupants when various modes of transport are compared. Some authors neither state which values they have used nor the assumptions that the results are based upon (i.e., [6,8]) only Brunner et al. [7] explained the estimation of the values in detail. The values are based on surveys, data from public transport providers and test drives in Graz (Austria). However, the number of observations/test runs performed is not specified. Shin et al. [8] only stated the final time-area requirements and not the instantaneous area requirements. Bruun's et al. [6] assumed car occupancy rates appear large with four people per car. UK government figures quote the average occupancy for a car as 1.6 [11].

Table 1. Instantaneous area requirements for various modes of transport.

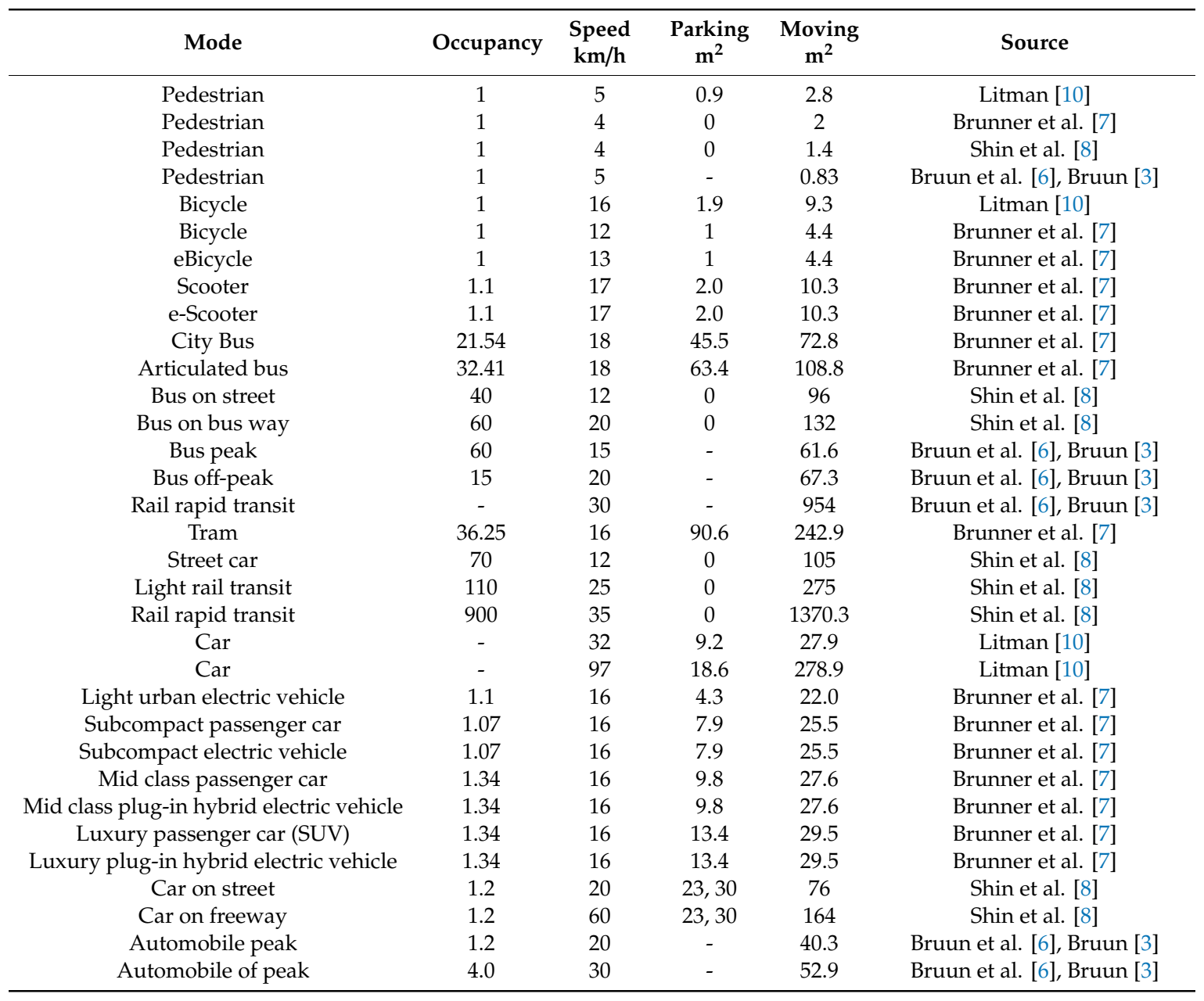

\subsection{Safe Operation (Discrete Formulation) Vs. Provided Infrastructure (Continuous Formulation)}

The time-area requirements can either be based on the instantaneous area requirements for safe operation or on the share of provided infrastructure. Considering only the time-area requirements for safe operation underestimates the time-area for modes of transport on dedicated infrastructures (e.g., trains, bus rapid transit systems) if they are not operating at full capacity (i.e., safe separation distance is smaller than the headway). Considering the share of provided infrastructure may not represent the true potential of a transport system, which might not run at full capacity due to restricted utilisation (e.g., due to COVID-19 restrictions) which could have the smallest time-area requirements 
when running at capacity. For example, a bicycle lane network might not run at full capacity until the entire network is built and residents get used to cycling. Estimating the share of provided infrastructure is also difficult if multiple modes of transport share the same infrastructure (e.g., passenger cars, commercial vehicles and busses). In addition, the difference between the time-area requirements for safe operation and the share of provided infrastructure can be large: Los Angeles had 1.4 lane miles per 1000 people, who travelled 23 miles each per day in 2000 [12]. If private cars were the only vehicles on the road, the resulting share of infrastructure is $2253 \mathrm{~m}$ of lane per person per day, or $8100 \mathrm{~m}^{2} \times \mathrm{min}$. The same $37 \mathrm{~km}$ trip requires 1935-6383 (Litman [10]), 3274 (Brunner et al. [7]), 900-3730 (Bruun et al. [6]) and 5069-6993 $\mathrm{m}^{2} \times \min$ (Shin et al. [8]). Note: Shin et al. [8] is based on a continuous flow estimation and is, therefore, relatively close to the example calculation of the share of the provided infrastructure.

Estimating the time-area requirements of standing vehicles has the same problem. Either the share of all parking spots can be considered or only the used parking spots. Due to the high utilisation of parking spaces in some cities, it might appear appropriate to consider parking spots only for the duration they are occupied within in the time-area calculation. In reality, the parking turnover rate ranges from 1.8 in furniture stores [13] up to 314.6 for convenience stores [13] per day and 0.4 to 1.4 per hour with an $80-90 \%$ occupancy rate [14]. A vehicle requires, on average, $2-3$ parking spaces in selected cities in the USA $[15,16]$. Table 2 summarises the complexities within the time-area estimation research domain.

Table 2. Comparison of time-area estimation methods.

\begin{tabular}{|c|c|c|}
\hline & $\begin{array}{l}\text { Required for Safe Operation } \\
\text { (Discrete Formulation) }\end{array}$ & $\begin{array}{c}\text { Provided Infrastructure } \\
\text { (Continuous Flow Formulation) }\end{array}$ \\
\hline $\begin{array}{l}\text { Transport } \\
\text { Activity }\end{array}$ & $\begin{array}{l}\text { + Estimates the minimum legal requirement } \\
\text { which can be reached if the infrastructure is } \\
\text { used at full capacity } \\
\text { + Can be used when multiple modes share the } \\
\text { same right-of-way } \\
\text { - People might keep larger distances } \\
\text { than required } \\
\text { - Underestimates the time-area requirements } \\
\text { given that unused space is not considered } \\
\text { even if it cannot be used for anything else }\end{array}$ & $\begin{array}{l}\text { + More accurate representation of the } \\
\text { provided infrastructure } \\
\text { - Punishes transport systems that do not run } \\
\text { at a high capacity but could run at a higher } \\
\text { capacity without additional infrastructure. } \\
\text { Thus, it assesses the provision of } \\
\text { infrastructure, not the vehicle itself. } \\
\text { - Difficult to estimate when multiple modes of } \\
\text { transport share the same right-of-way }\end{array}$ \\
\hline Parking & $\begin{array}{l}\text { + Estimates the minimum which can be } \\
\text { reached if the infrastructure is used at } \\
\text { full capacity } \\
\text { - Underestimates the fact that most cities } \\
\text { provide multiple parking spots per car }\end{array}$ & $\begin{array}{c}\text { + Accounts for the entire } \\
\text { provided infrastructure } \\
\text { - Overestimates demand if parking is not } \\
\text { utilised at full capacity, e.g., due to a } \\
\text { planning error } \\
\text { - Difficult to estimate when a parking spot is } \\
\text { used by multiple vehicles during a day } \\
\text { - The number of available parking spots is } \\
\text { difficult to estimate due to on-street parking }\end{array}$ \\
\hline
\end{tabular}

The method should be chosen according to the application area. This study uses time-area for safe operation for driving and parking (discrete formation) given that delivery vehicles share the road with other road users, and it represents the legal minimum of the time-area requirement.

\subsection{Value of Land}

The time-area metric considers all land equally and does not differentiate between the value of land. Some might argue that land in rural areas is not as valuable as land in the city centre, that a parking spot at a depot might not be as bad as an additional parking spot in the city centre, or traveling on a rural motorway might be less damaging than traveling in the city. However, the aim of the time-area concept is not to judge the land consumption depending on the value of the land, as this is 
subjective. For instance, the financial value of land varies depending on the time, type of land and the value of surrounding areas. Considering the financial value of the land in the time-area calculation is problematic as it would mean that all traffic gets diverted into poor neighbourhoods, where the land is less expensive, even though the trip would be multiple times as long. Thus, instead of reducing the area required for transport activities, more streets would be required due to the increased travel. Especially nowadays, with the focus on equality, it would be questionable to consider the land in poor neighbourhoods less valuable and therefore put less effort into optimising the traffic to reduce land consumption compared to rich neighbourhoods. It might be argued that rather the social cost (i.e., internal and external cost) or only the external cost of land should be considered. The external cost of land can be high in rural areas due to the fragmentation of habitats and ecosystems by streets. In short, the time-area concept aims to reduce land consumption and, therefore, should not consider the financial value of the land. If the financial value would be considered, the traffic would be diverted into poor neighbourhoods, even if this would be a detour, which increases the required area for streets. Thus, the time-area concept needs to consider all land equally. By doing so, it supports policymakers in allocating land more effectively, given that every square meter devoted to roads is lost for other purposes, irrespective of the value of the land.

\section{Methods}

\subsection{Formula}

According to Bruun [3], separate time-area equations are required for congested and free flow due to the mechanics and mathematics of modelling vehicle flow. However, this is not the case and the average speed can be used instead if the time-area for safe operation (i.e., legally required area) is adopted, since drivers are taught/legally required to keep a $2 \mathrm{~s}$ separation distance in most parts of Europe [17]. If the headway between two vehicles is larger than the $2 \mathrm{~s}$ separation, then the additional area is regarded as unused capacity and not attributed to the vehicle.

The proposed time-area equation includes a safety distance $s_{i}$ in addition to the $2 \mathrm{~s}$ separation distance to ensure sufficient separation at low speeds and when parking. An additional one metre distance in front of a van is sufficient for parallel parking, which delivery vans use $95 \%$ of the time in London [18]. The equation can be used in any traffic flow situation, as well as for parking (Figure 3).

$$
T A_{i}=\left(l_{i}+s_{i}+\left(\frac{t_{s} * \mathrm{~d}_{\mathrm{i}}}{\mathrm{t}_{\mathrm{i}}}\right)\right) * w_{i} * t_{i}
$$

Transformed into:

$$
\mathrm{T} A_{i}=\left(\left(l_{i}+s_{i}\right) * t_{i}+\left(t_{s} * \mathrm{~d}_{\mathrm{i}}\right)\right) * w_{i}
$$

where

$T A_{i}$ Time-area required for trip;

$l_{i} \quad$ Length of vehicle;

$s_{i} \quad$ Safety distance between standing vehicles;

$\mathrm{d}_{\mathrm{i}} \quad$ Trip distance;

$t_{i} \quad$ Trip duration;

$w_{i} \quad$ Width of the lane/right-of-way;

$t_{s} \quad$ Following rule (usually two seconds).

To transfer Equation (16) into a continuous formulation, $t_{s}$ has to be replaced with the average headway and $s_{i}$ is set to 0 . Note: this continuous formulation only applies to moving vehicles. 


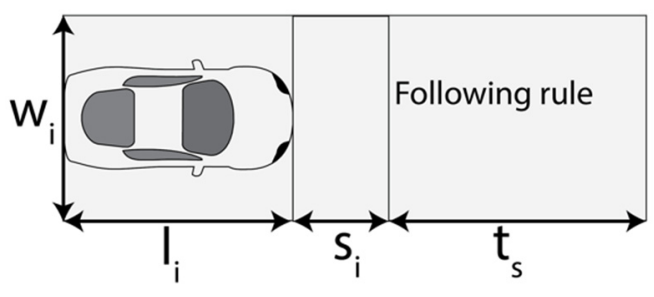

Figure 3. Specifications of the simulation.

It is not necessary to use an integral when the speed is not constant, as shown in Equation (18), when the following distance is assumed to be the legal requirement (e.g., $2 \mathrm{~s})$. However, this may not necessarily represent actual driving behaviour. The left side of the equations calculates the safe separation distance for every timestamp and then takes the average over the time period. The right-hand side takes the average of the speed and then calculates a safe separation distance. It should be noted that the integral is over the travel time $t$ and not $t_{s}$ the safe separation distance (i.e., $2 \mathrm{~s}$ ).

$$
\begin{gathered}
\frac{1}{T} * \int_{0}^{T} v_{t} * t_{s} * w d t=t_{s} * w * \frac{\int_{0}^{T} v_{t} d t}{T}=t_{s} * w * \bar{v} \\
A_{S}=\frac{1}{T} * \sum_{t=0}^{T} v_{t} * t_{s} * w=t_{s} * w * \frac{v_{0}+v_{1}+\cdots+v_{T}}{T}=t_{s} * w * \bar{v}
\end{gathered}
$$

where

$A_{s} \quad$ Area of the safety gap to the vehicle in the front;

$t_{s} \quad$ Following rule (i.e., $2 \mathrm{~s}$ );

$v_{t}$ Velocity at timestamp $\mathrm{t}$;

$T$ Trip duration;

$w$ Width of the lane/right-of-way.

The average speed should be calculated based on the exact trip duration and distance to ensure that the exact traffic flow, driving behaviour and waiting at intersections is considered. It is also not necessary to define a two-dimensional coordinate system when the path is not straight. The area is the same, regardless of whether the area is on a circle or on a straight line, as shown in the following equation:

$$
A_{r}=\pi *\left(r+\frac{w}{2}\right)^{2}-\pi *\left(r-\frac{w}{2}\right)^{2}=\pi\left(r^{2}+\frac{w^{2}}{4}+w r-r^{2}-\frac{w^{2}}{4}+w r\right)=2 \pi r * w=l * w
$$

where

$A_{r} \quad$ Area of a circular ring/area of street;

$r$ Radius;

$w$ Width of the street;

$l \quad$ Length of the street/circumference.

Only a small inaccuracy occurs at the intersection between the front buffer area (grey) and the vehicle buffer area (red), as shown in Figure 4. The blue area is not included, while the green area is counted twice. However, this is not a problem, as both areas are almost the same size, according to [3]. 


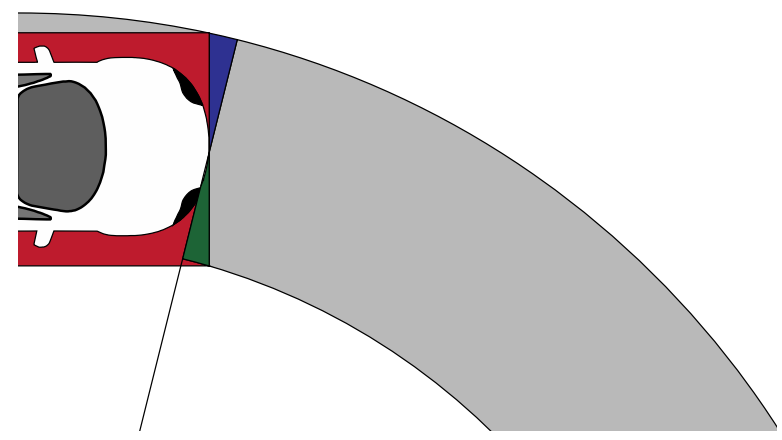

Figure 4. Buffer area around vehicle and shadow area in a turn. Buffer area around vehicle (red), double considered area (green), not considered area (blue), and front buffer area (grey).

The calculation method assumes that the vehicles follow the traffic flow. In other words, the vehicle drives as the traffic flows and parks in parking spots. However, delivery vehicles are known for illegal double parking, which disrupts the traffic flow by blocking a lane and, therefore, reduces the capacity of the road. Hence, the proposed calculation method would underestimate the time-area requirement if the vehicle parks illegally. However, this has been ignored in this study as the calculation only considers the legally required area for the safe operation of the vehicles, even though it might not fully represent actual driving behaviour.

\subsection{Pedestrians}

The space requirements for a moving pedestrian published in previous studies ranges from $0.83 \mathrm{~m}^{2}$ Bruun et al. [6] to $2.8 \mathrm{~m}^{2}$ Litman [10]. The minimum footpath width is $1.5 \mathrm{~m}$ [19] and the recommended width of a footpath is $2 \mathrm{~m}$, which allows two people in a wheelchair to pass each other [19]. In this paper, the average $(0.875 \mathrm{~m})$ has been used as the width of the right-of-way $w_{i}$. In the USA, the Highway Capacity Manual requires a minimum width of $0.8 \mathrm{~m}$ [20]. The length $0.875 \mathrm{~m}$ has also been used as the combination of safety distance $s_{i}$ and length $l_{i}$. Given that pedestrians can change direction and stop quickly the $1 \mathrm{~s}$ following rule has been applied. The resulting instantaneous area requirements are illustrated in Table 3. At average walking speeds, these instantaneous time-area requirements correspond to a pedestrian facilities level of service of $C$, according to the scale in [20].

Table 3. Instantaneous area requirements for pedestrians.

\begin{tabular}{cccccc}
\hline $\mathbf{k m} / \mathbf{h}$ & 0.0 & 1.8 & 3.6 & 5.4 & 7.2 \\
\hline Pedestrian $\left(\mathbf{m}^{\mathbf{2}}\right)$ & 0.8 & 1.2 & 1.6 & 2.1 & 2.5 \\
Pedestrian with $\mathbf{b a g}\left(\mathbf{m}^{\mathbf{2}}\right)$ & 1.5 & 2.0 & 2.4 & 2.8 & 3.3 \\
\hline
\end{tabular}

\subsection{Bicycles and Cargo Bikes}

Bicycles are assumed to follow the $2 \mathrm{~s}$ rule, given that a cyclist needs to react and apply the brakes, similar to a car driver. This is in line with the findings of Greibe et al. [21], who observed a maximum flow of 20-25 cyclists per $20 \mathrm{~s}$ on a two-lane cycle path based on 8925 cyclists.

Brunner et al. [7] and Litman [10] recommended 4.4 and $9.3 \mathrm{~m}^{2}$ for a moving cyclist, respectively. Brunner et al. [7] assumed that three bicycles can fit on a $3 \mathrm{~m}$ wide road. Thus, they assumed a headway between two cyclists of $2.6 \mathrm{~m}(4.4 \mathrm{~m}$ minus bike length of $1.8 \mathrm{~m})$. The distance travelled during a reaction time of $1 \mathrm{~s}$ by a cyclist at $9.5 \mathrm{~km} / \mathrm{h}$ is already longer than $2.6 \mathrm{~m}$. They assumed an average speed of $12 \mathrm{~km} / \mathrm{h}$. Thus, the $4.4 \mathrm{~m}^{2}$ suggested by Brunner et al. [7] might be large enough for a bicycle during a bicycle race, but it is too small for cycling in cities.

In the UK, the dynamic width (i.e., actual width plus deviation) of a cyclist is $1 \mathrm{~m}$ (as stated in LTN 2/08: Cycle Infrastructure Design [22]) and a $50 \mathrm{~cm}$ distance should be kept between two cyclists, $1 \mathrm{~m}$ to a car at $20 \mathrm{mph}$ and $1.5 \mathrm{~m}$ to a car at $30 \mathrm{mph}$. Thus, the minimum required width for a cyclist on 
a road is $1.5 \mathrm{~m}\left(w_{i}\right)$. The length of a typical bicycle is $1.8 \mathrm{~m}\left(l_{i}\right)$ [22]. The safety distance $s_{i}$ is assumed to be $0 \mathrm{~m}$, to account for the fact that, when standing, only the actual width of the bicycle is required and not the dynamic width. The difference between the area of the actual width and the dynamic width is assumed to be used as a safety distance when standing. At very low speeds, bicycles might even require more width than dynamic width to balance. This is ignored, as couriers should never intentionally ride at slow walking speeds. Greibe et al. [21] observed 8925 cyclists $(1.3 \%$ were cargo bicycles) and found out that bicycles kept between 0.6 and $0.8 \mathrm{~m}$ from the sidewalk when travelling in single file on a bike path. Thus, their total right of way was between $1.2 \mathrm{~m}$ and $1.6 \mathrm{~m}$. When one cyclist overtook another, the first cyclist kept $0.5 \mathrm{~m}$ to $0.7 \mathrm{~m}$ to the sidewalk and the second cyclist kept $1.4 \mathrm{~m}$ to $1.90 \mathrm{~m}$ to the sidewalk. Thus, the first cyclist used a right of way of approximately $1.125 \mathrm{~m}$, which is in line with the cycle path design recommendations [22]. The resulting instantaneous area requirements (Table 4) are larger than in the previously published studies (i.e., [7,10]), as explained before.

Table 4. Instantaneous area requirements for bicycles and electric bicycles.

\begin{tabular}{ccccccccccc}
\hline $\mathbf{k m} / \mathbf{h}$ & 0.0 & 3.6 & 7.2 & 11 & 14 & 18 & 22 & 25 & 29 & 32 \\
\hline $\mathbf{m}^{\mathbf{2}}$ & 2.7 & 5.7 & 8.7 & 12 & 15 & 18 & 21 & 24 & 27 & 30 \\
\hline
\end{tabular}

Most cargo bikes are around $2.6 \mathrm{~m}\left(l_{i}\right)$ long. It could be argued that the right-of-way of a cargo bike and a bicycle should be the same as they use the same right-of-way. However, according to Greibe et al. [21], cargo cyclists cycled 10-20 cm further away from the curb and kept a 1.3-times longer headway than normal cyclists, based on 8925 cyclists (of which $1.3 \%$ were cargo bicycles). Table 5 shows the resulting instantaneous area requirements.

Table 5. Instantaneous area requirements for cargo bicycles.

\begin{tabular}{ccccccccccc}
\hline $\mathbf{k m} / \mathbf{h}$ & 0.0 & 3.6 & 7.2 & 11 & 14 & 18 & 22 & 25 & 29 & 32 \\
\hline $\mathbf{m}^{\mathbf{2}}$ & 4.7 & 9.4 & 14 & 19 & 23 & 28 & 33 & 37 & 42 & 47 \\
\hline
\end{tabular}

\subsection{Vans and Trucks}

The Renault Kangoo, Fiat Doblo, Ford Transit Connect, and Volkswagen Caddy are examples of small sized vans. Their average length $l_{i}$ is $4.4 \mathrm{~m}$, based on the websites of the manufacturers. A safety distance of $1 \mathrm{~m}$ is assumed in this research. The suggested lane width of $2.75 \mathrm{~m}\left(w_{i}\right)(\mathrm{min} .2 .45 \mathrm{~m})$ [19] results in $45 \mathrm{~cm}$ to the left and right of the vehicle, which is enough for the driver to enter and exit the van. The resulting time-area requirements (Table 6) utilised in this research are similar to those reported in the published literature, which ranges from $27.6 \mathrm{~m}^{2}$ [7] to $75.6 \mathrm{~m}^{2}$ [8] in cities.

Table 6. Instantaneous area requirements for vans and trucks in $\mathrm{m}^{2}$.

\begin{tabular}{ccccccccc}
\hline Speed $\mathbf{( k m} / \mathbf{h})$ & 0 & 7.2 & 14 & 22 & 29 & 36 & 50 & 65 \\
\hline Small van $\left(\mathbf{m}^{\mathbf{2}}\right)$ & 15 & 26 & 37 & 48 & 59 & 70 & 92 & 114 \\
Medium van $\left.\mathbf{( m}^{\mathbf{2}}\right)$ & 16 & 27 & 38 & 49 & 60 & 71 & 93 & 115 \\
$\mathbf{3 . 5} \mathbf{t}$ van $\left(\mathbf{m}^{\mathbf{2}}\right)$ & 19 & 30 & 41 & 52 & 63 & 74 & 96 & 118 \\
$\mathbf{7 . 5} \mathbf{t}$ lorry $\left(\mathbf{m}^{\mathbf{2}}\right)$ & 27 & 46 & 65 & 84 & 104 & 123 & 161 & 200 \\
\hline
\end{tabular}

The Ford Transit Custom, Renault Traffic, Mercedes Vito, and VW Transporter are examples of medium sized vans. The Ford Transit L3, Renault Master, Mercedes Sprinter L2, and VW Crafter are examples of $3.5 \mathrm{t}$ large sized vans. Trucks (i.e., gross weight $7.5 \mathrm{t}$ ) are represented by the Fuso Canter (Daimler Group), Mercedes Atego, Isuzu Forward, and IVECO ML. The average lengths of these vehicles, taken from the websites of the manufacturers, are $4.9,5.9$, and $6.7 \mathrm{~m}$, respectively. In this research, $s_{i}=1 \mathrm{~m}$ is adopted except for $7.5 \mathrm{t}$ trucks, which are assumed to require a $3 \mathrm{~m}$ safety gap due 
to the higher seating position of the driver and the larger manoeuvring area required when parking. In addition, the following vehicle rule has been increased to $6 \mathrm{~s}$, as $7.5 \mathrm{t}$ trucks are required to observe a larger separation distance in some countries, including France (50 m outside the city), Germany (50 m if speed $>50 \mathrm{~km} / \mathrm{h}$ ), and Austria (always $50 \mathrm{~m}$ ) [17]. The resulting headway is illustrated in Table 7 .

Table 7. Headway for vans and trucks.

\begin{tabular}{ccccccccccc}
\hline $\mathbf{~ k m} / \mathbf{h}$ & 0 & 7 & 14 & 22 & 29 & 36 & 43 & 50 & 58 & 65 \\
\hline All vans (m) & 1 & 5 & 9 & 13 & 17 & 21 & 25 & 29 & 33 & 37 \\
$\mathbf{7 . 5} \mathbf{t}$ lorry (m) & 3 & 10 & 17 & 24 & 31 & 38 & 45 & 52 & 59 & 66 \\
\hline
\end{tabular}

\subsection{Sidewalk Automated Delivery Robots (SADRs)}

The size of SADRs is based on the Starship delivery robot (width $0.569 \mathrm{~m}$, length $0.678 \mathrm{~m}$ [23]). Given that SADRs share the footpath with pedestrians, they should behave as a pedestrian to ensure that they do not become obstacles. Thus, they cannot require a larger time-area than a pedestrian. This leaves a $15 \mathrm{~cm}$ gap on either side of the SADR and $10 \mathrm{~cm}$ towards the front and back while standing. The resulting instantaneous area requirements are illustrated in Table 8.

Table 8. Instantaneous area requirements for SADRs.

\begin{tabular}{cccccc}
\hline $\mathbf{k m} / \mathbf{h}$ & 0.0 & 1.8 & 3.6 & 5.4 & 7.2 \\
\hline $\mathbf{m}^{\mathbf{2}}$ & 0.8 & 1.2 & 1.6 & 2.1 & 2.5 \\
\hline
\end{tabular}

\subsection{Simulation Specifications}

Table 9 shows the specifications for the time-area simulation. OSRM Speed Profile refers to the name of the speed profile in the Open Source Routing Machine (OSRM). $l_{i}$ is the length of the vehicle, $s_{i}$ is the safety distance between standing vehicles, $w_{i}$ is the width of the lane or right-of-way, and $t_{\mathrm{s}}$ is the following rule (usually, two seconds have to be kept between two vehicles while driving).

Table 9. Simulation specifications.

\begin{tabular}{cccccc}
\hline Mode & $\begin{array}{c}\text { OSRM Speed } \\
\text { Profile }\end{array}$ & $\begin{array}{c}\boldsymbol{l}_{\boldsymbol{i}}(\mathbf{m}) \\
\text { Length }\end{array}$ & $\begin{array}{c}\boldsymbol{s}_{\boldsymbol{i}}(\mathbf{m}) \\
\text { Safety Distance }\end{array}$ & $\begin{array}{c}\boldsymbol{w}_{\boldsymbol{i}}(\mathbf{m}) \\
\text { Width }\end{array}$ & $\begin{array}{c}\boldsymbol{t}_{\boldsymbol{s}}(\mathbf{s}) \\
\text { Following Rule }\end{array}$ \\
\hline Pedestrian & Pedestrian & 0.875 & 0 & 0.875 & 1 \\
Pedestrian with bag & Pedestrian & 1.75 & 0 & 0.875 & 1 \\
Bicycle & Bicycle & 1.8 & 0 & 1.5 & 2 \\
Cargo bike & Bicycle & 2.6 & 0 & 1.8 & 2 \\
Small van & Car & 4.4 & 1 & 2.75 & 2 \\
Medium van & Car & 4.9 & 1 & 2.75 & 2 \\
3.5 Tonne van & Car & 5.9 & 1 & 2.75 & 2 \\
7.5 Tonne lorry & Car & 6.7 & 3 & 2.75 & 6 \\
SADR & Pedestrian & 0.678 & 0.197 & 0.875 & 1 \\
\hline
\end{tabular}

\subsection{Application to Delivery Trip Data}

The decision support method has been used to evaluate the time-area requirements of Gnewt, a delivery company in London [24]. The data set includes more than 13,000 delivery trips between July 2015 and June 2016, during which 2 million parcels were successfully delivered in London. In the dataset, $30 \%$ of the delivery trips had to be excluded due to missing or wrong data. Each delivery trip includes the components illustrated in Figure 5. 


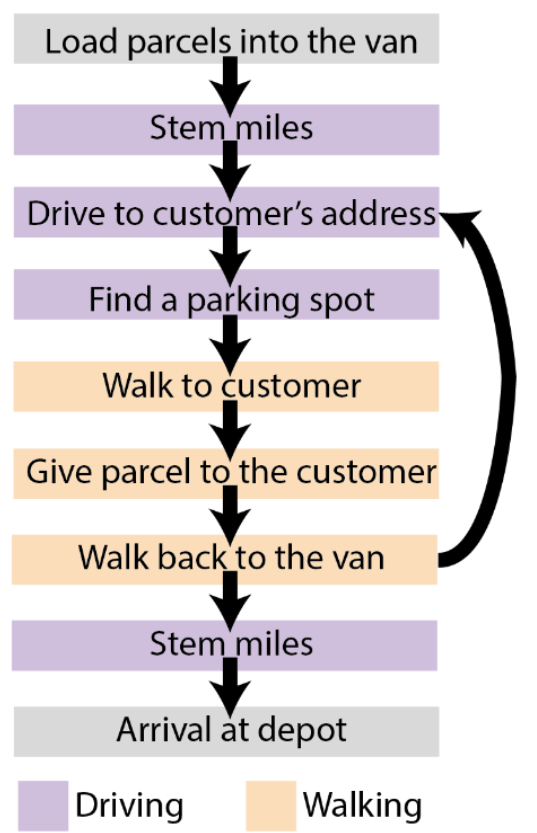

Figure 5. Components of a delivery trip.

Given that the trip data set does not include information about the walking distance or duration, it is assumed that the walking distance accounted for $40 \%$ of the total delivery distance (i.e., driving + walking) and $62 \%$ of the total round-trip time, as determined in a study in London, based on 25 trips [18]. It is unknown whether the parking spot at the depot is used for something else during a delivery. Hence, the time-area requirements have been calculated twice, such that (i) the parking spot at the depot is used for something else during the delivery (i.e., only the time the parking spot is used by the delivery van accounts for the time-area requirement) and (ii) the parking spot at the depot is considered as a contributing factor during the delivery as well. The time-area requirements are calculated per trip and divided by the number of parcels per trip to determine the time-area metric.

\subsection{Limitations}

Not every delivery van has a trip every day in the dataset; for example, on Sundays or because the trip has been deleted as part of the data-cleaning process. Thus, vans are only considered (i.e., require a parking spot at the depot) on a day they have deliveries. The study only considers the area of the depot required to park the vans, not the parcel sorting area.

\section{Results}

\subsection{Time-area Requirements}

While the previous section of the paper explains the time-area requirement calculation for various modes of transport, only the time-area requirements of delivery vans are compared in this paper as an example. Figure 6 illustrates the time-area requirement of each aspect of the delivery trip per parcel (Driving: delivery van while driving between customers; Van Standing: delivery van being parked during a delivery trip; Driver Walking: driver walking to and from the customer to the delivery van; Parking at Depot: only the time the delivery van is parked at the depot is considered; $24 \mathrm{~h}$ parking: parking spot at a depot for $24 \mathrm{~h}$ ). The figure highlights the variation of the time-area requirements per parcel between trips and the difference in the time-area requirements between each aspect of the delivery trip. The time-area requirement per parcel while delivering parcels (mean: $29 \mathrm{~m}^{2} \times \mathrm{min}+$ $31 \mathrm{~m}^{2} \times \mathrm{min}+3 \mathrm{~m}^{2} \times \mathrm{min}$ ) is much smaller than the time-area requirement of a parking spot at the depot for $24 \mathrm{~h}$ (mean: $169 \mathrm{~m}^{2} \times \mathrm{min}$ ). 


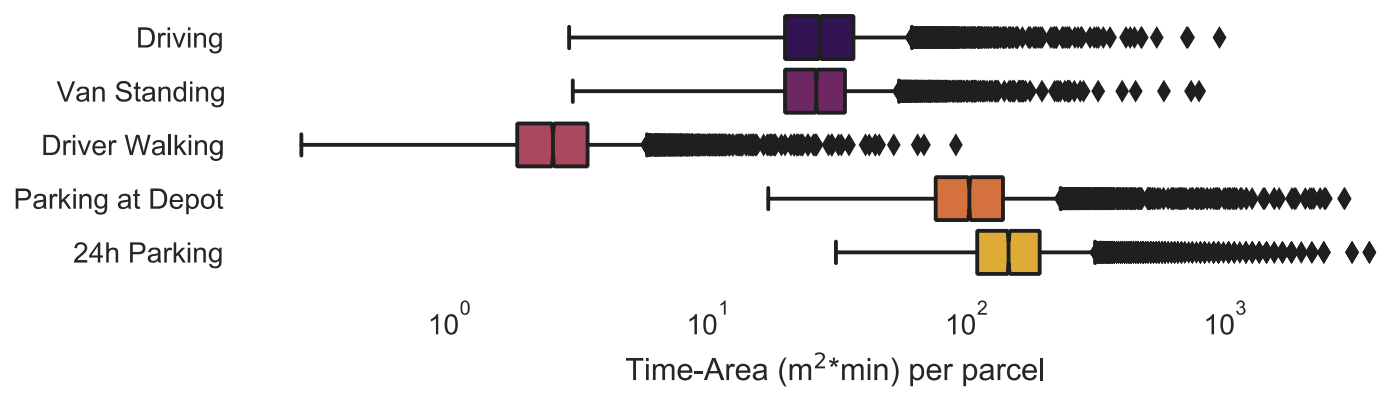

Figure 6. Time-area requirements per parcel (logarithmic scale).

Figures 7 and 8 are based upon the situation where the parking spot at the depot is required 24/7. Figure 7 shows the time-area requirement per parcel for each month and the average number of parcels delivered per day (green line). Note that all data from February had to be deleted in the data-cleaning process. The time-area requirements per parcel are highest in October. December, the month with the lowest time-area requirements, sees the highest number of parcel deliveries per day. October, the month with the lowest number of parcels (60\% of December), has 50\% higher time-area requirements than in December. Overall, it can be seen that the time-area requirements per parcel are decreasing with an increasing number of parcels delivered per day.

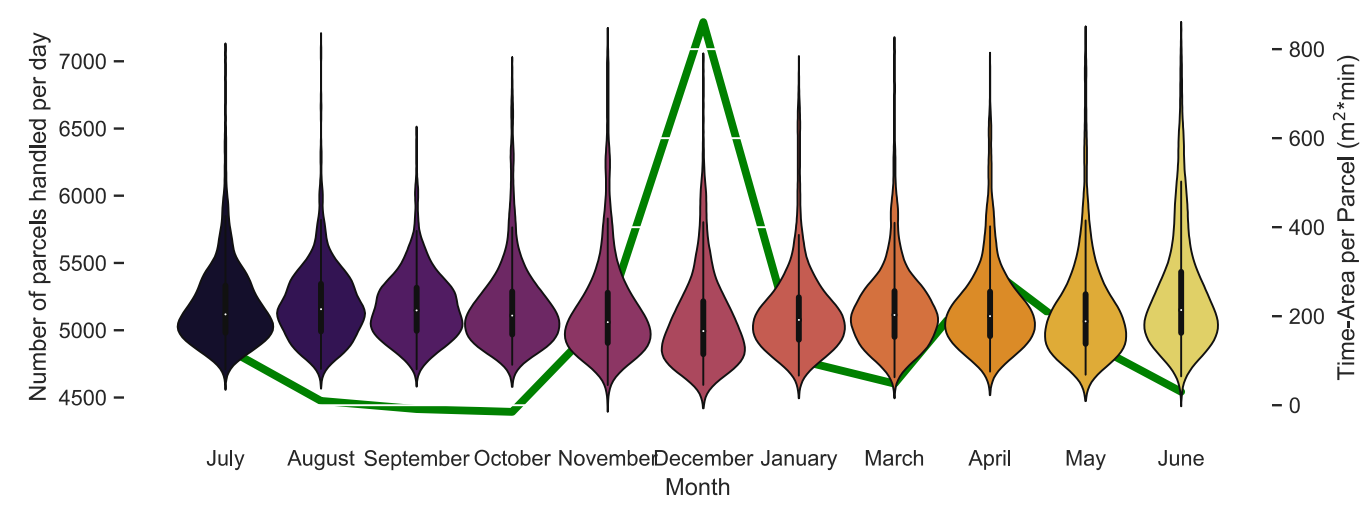

Figure 7. Time-area requirements per parcel (violins) and average number of parcels per day (green line) (Month) (Depot 24 h).

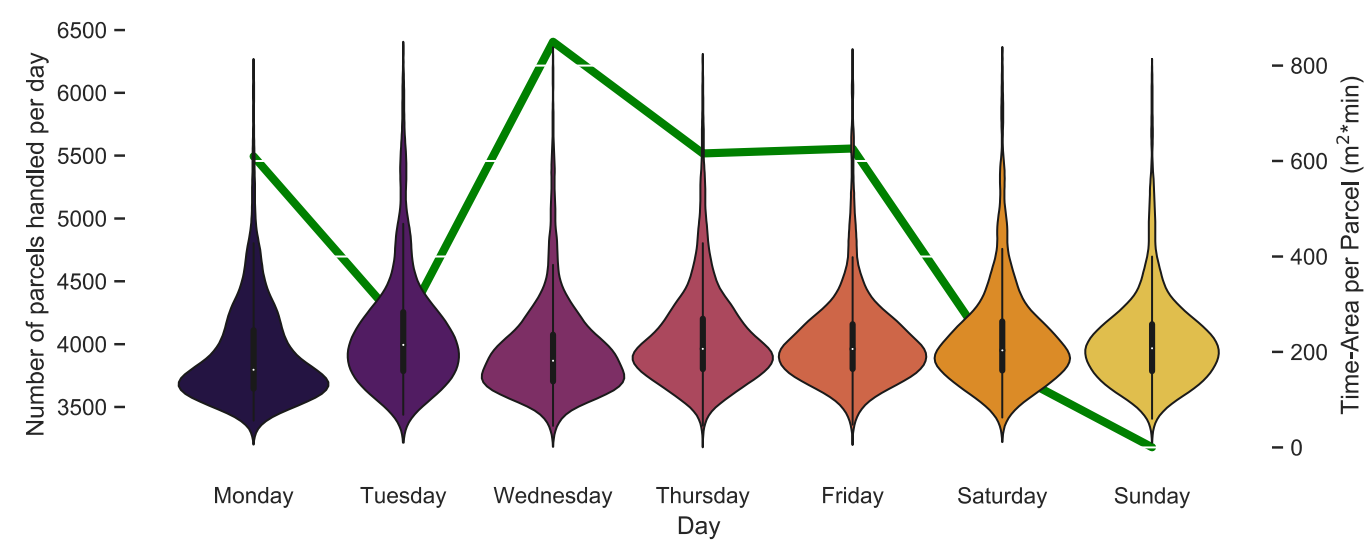

Figure 8. Time-area requirements per parcel (Violins) and average number of parcels per day (green line) (day of the week) (Depot $24 \mathrm{~h}$ ).

A similar picture can be seen in the time-area requirement per parcel for each day of the week. Sunday is the day with the highest time-area requirement per parcel and the lowest number of parcels 
delivered per day. On Wednesday, the average number of delivered parcels per day is twice as high and the time-area requirement per parcel is $25 \%$ lower.

\subsection{Correlations}

Due to the large variation in the time-area requirements per parcel between trips, it would be beneficial to investigate why some delivery trips use space more efficiently than other trips. The correlations between the time-area requirements (e.g., total time-area requirements, during driving walking, parking) and key performance indicators have been calculated based on the Pearson, Spearman, and Kendall correlation.

The number of parcels per delivery route and the total time-area requirement have a strong negative correlation (Spearman: -0.99 , Kendall: -0.95 , Pearson: -0.55 ). The Pearson correlation is lower as it assumes a linear relationship and the relationship is not linear, as can be seen in Figure 9 . The correlations are similar, regardless of whether the total time-area requirements or the time-area requirements of each component of the delivery trip (walking, driving, etc.) are considered. The key performance indicators per parcel are generally correlated with the total time area requirements, such as handover time per parcel (Spearman: 0.79, Kendall: 0.61, Pearson: 0.81) or distance per parcel (Spearman: 0.70, Kendall: 0.61, Pearson: 0.68). However, all other key performance indicators in Figure 9 are not correlated with the time-area requirements.
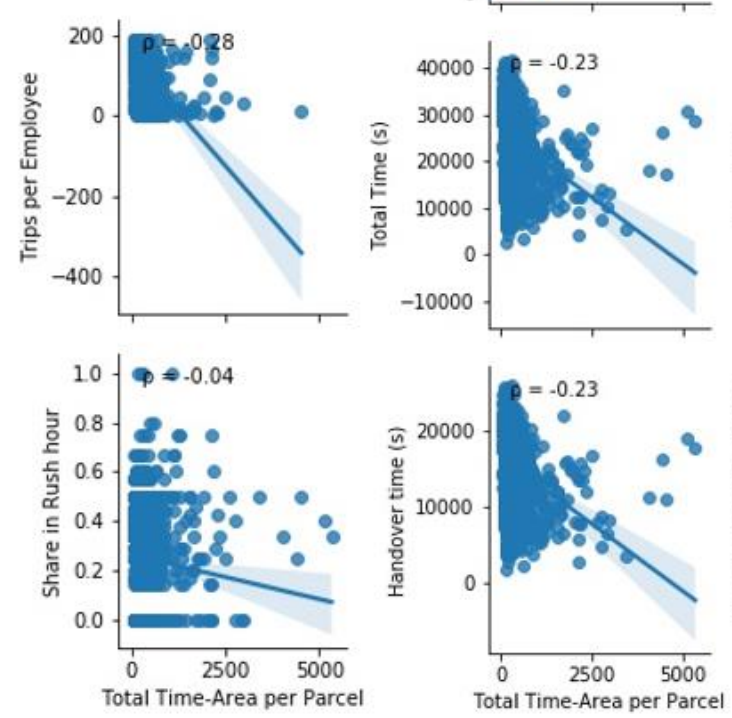
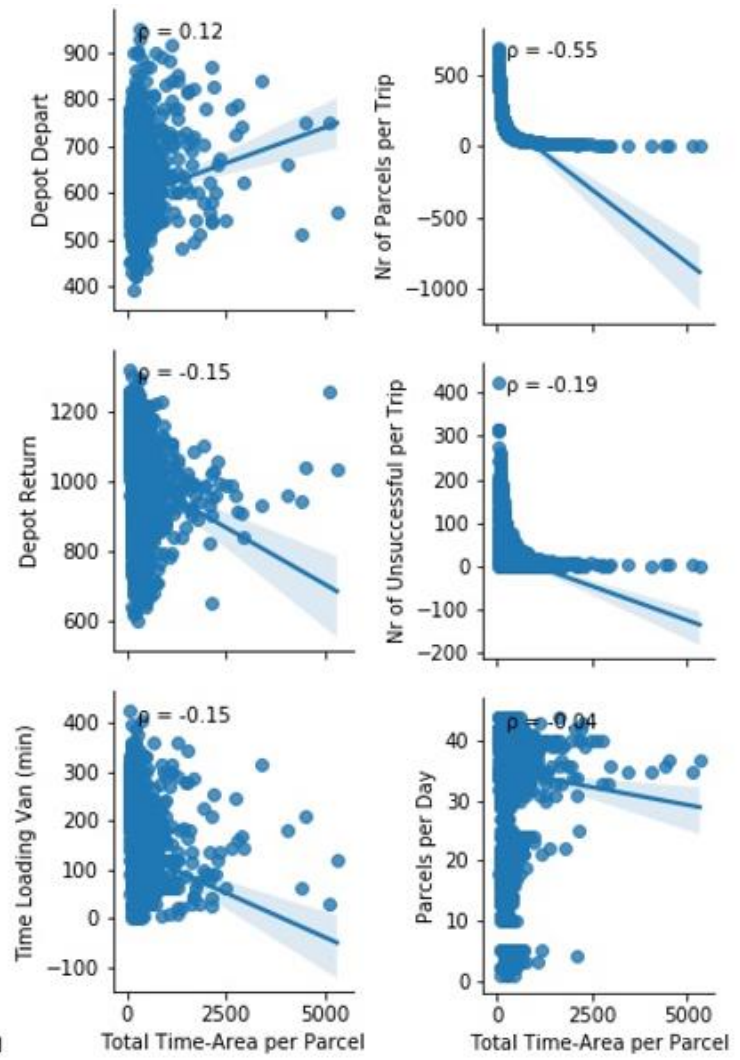

Figure 9. Pearson correlations between key performance indicators and time-area requirements (depot parking not considered for $24 \mathrm{~h}$ ).

\subsection{Policy and Operating Strategy Changes}

Figure 10 illustrates the effect changes in the policies and operating strategies have on the time-area requirements. In the figure it is assumed that reserved parking spots could reduce the distance and time drivers travel by either $20 \%$ or $40 \%$, delivering to parcel lockers could reduce the handover time by $60 \%, 80 \%$, and $100 \%$, and having two drivers per van handing over parcels at the same time could 
reduce the handover time by $20 \%$ or $40 \%$. In all of these cases, the reduction in the total time-area requirements is neglectable, as the reduction in travel time is compensated by an increase in the time parked at the depot (i.e., delivery vans will not deliver more parcels per day even though the delivery time is reduced). If the parking at the depot is ignored, reserved parking reduces the time-area requirements by $10 \%$ or $19 \%$, lockers by $31 \%, 41 \%$, or $51 \%$, and two drivers by $11 \%$ or $21 \%$. Thus, only policy or operating strategy changes have a significant effect, if the number of parcels delivered per van per day is increased in accordance with the reduction in delivery time. The biggest changes in the time-area requirement can be achieved by increasing the size of the delivery van, which increases the total time-area requirements by up to $87 \%$ and the time-area requirements of only the delivery trip by up to $100 \%$. Thus, parcel delivery companies should fit the maximum number of parcels that can be delivered during one shift into the smallest possible van.

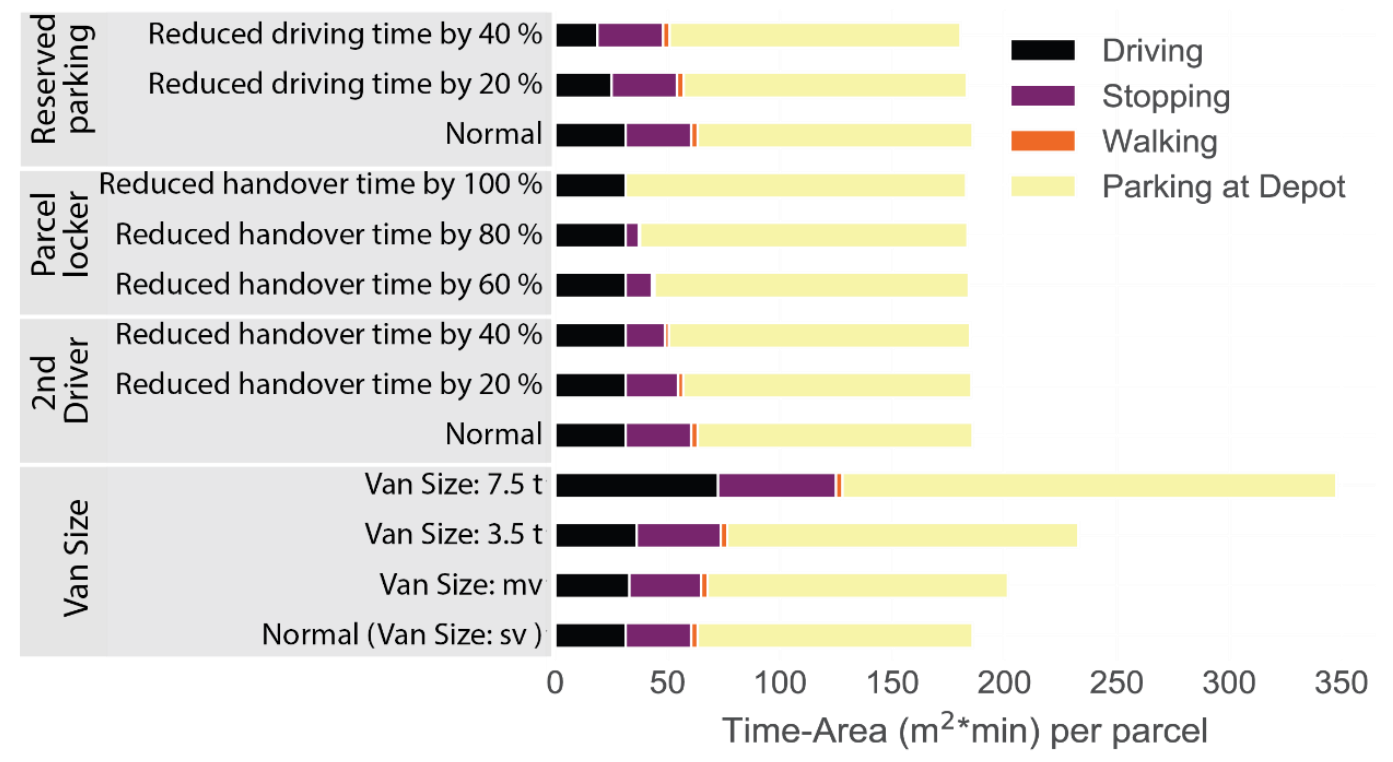

Figure 10. Effects of changes in the operating strategy and policy on the time-area requirements (depot not $24 \mathrm{~h})$.

It should be noted that not every policy change can be evaluated based on the time-area calculation proposed in this study. The effect of changes in the traffic flow due to policy changes can generally not be evaluated unless the policy changes the following rule. For example, the effect delivery bay management has on the delivery time and distance [25] can be considered in the proposed time-area calculation, while the changes in the traffic flow due to delivery bay management cannot. Dynamic delivery parking spots [26] are considered as an option to improve traffic flow and increase the capacity of the road by reducing the number of vehicles illegally blocking a lane (i.e., double parking). However, the proposed time-area equation only considers the legally required area for safe operation. Thus, the improvement in the traffic flow due to dynamic parking areas and therefore increased capacity of the road and cannot be evaluated. Only the reduction in delivery time and distance can be evaluated similar to reserved parking spots. The improvement in the traffic flow due to dynamic parking areas can only be evaluated if a continuous flow formulation is adopted in the time-area calculation.

\subsection{Sensitivity Analysis}

A sensitivity analysis was conducted to cover variations in $l_{i}$ (length of vehicle), $w_{i}$ (width of the lane/right-of-way), $s_{i}$ (safety distance between standing vehicles), $\mathrm{t}_{\mathrm{s}}$ (following rule), and $\mathrm{f}_{\mathrm{i}}$ (increase in delivery duration due to traffic). It is assumed that the parking spot at the depot is used for something else during the delivery and, therefore, the parking spot at the depot is only added to the time-area requirements for the duration it is in use (i.e., overnight) and not while the delivery vehicle is delivering 
parcels. Figure 11 shows the increase in the time-area requirements for a specific aspect of the delivery trip if the previously mentioned input variables $\left(l_{i}, w_{i}, s_{i}, t_{s}\right.$, and $\left.\mathrm{f}_{\mathrm{i}}\right)$ are multiplied by 1.2 . When the width of the vehicle and delivery courier is increased, the time-area requirements increase correspondingly. Increasing the vehicle length has a smaller effect on the time-area requirement $(11-16 \%)$. When the delivery driving duration is increased by $20 \%$ the parking spot at the depot is required for a shorter time; hence, the time-area requirement of the parking spot at the depot is reduced by $8 \%$. If either the safety distance or following rule is increased, the time-area requirements increase by $0-9 \%$. Overall, reducing the ground area of the vehicle (length and width) reduces the time-area requirement the most.

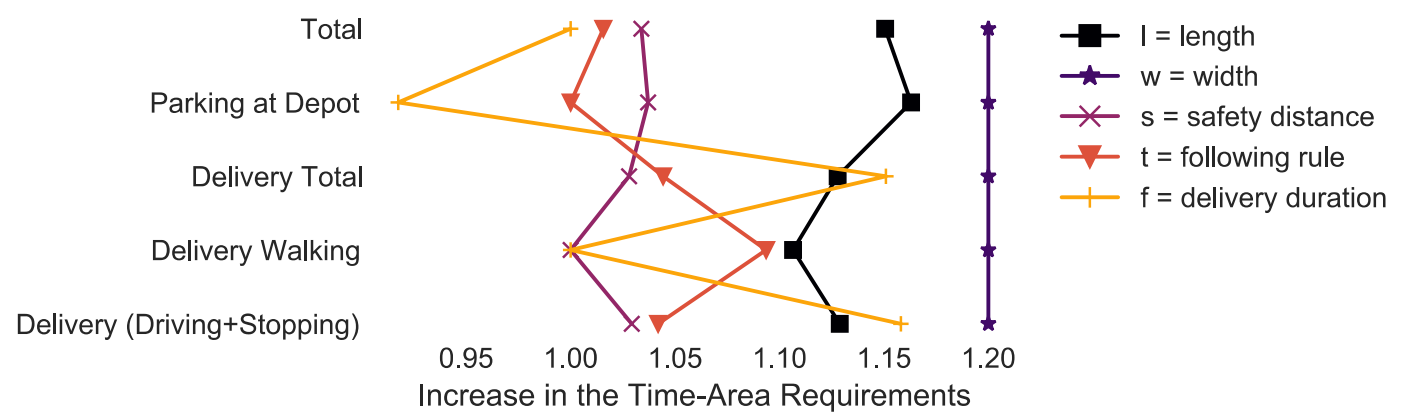

Figure 11. Sensitivity analysis $(\mathrm{l}=$ length, $\mathrm{w}=$ width, $\mathrm{s}=$ safety distance, $\mathrm{t}=$ following rule, $\mathrm{f}=$ delivery duration) showing the effect of increasing these variables by 1.2.

\section{Conclusions}

The time-area concept can be used by policymakers to allocate space effectively in cities to maximise welfare. This is important, as every $\mathrm{m}^{2}$ devoted to streets is lost for housing and parks in cities or habitats and ecosystems in rural areas. While the main application area is in macro-economic decision making, it can also be used to calculate the opportunity cost and external cost, which can be internalised as, e.g., road pricing.

Despite its advantages and possible use cases, the time-area concept is mainly used in anecdotal books and the number of scientific publications is limited. The publications are usually limited to a few example trips with many assumptions instead of evaluating an entire simulation or transport system (apart from Schnieder et al. [5]). Thus, these publications are unsuitable for policymakers. This paper addresses this problem by reviewing and proposing an evaluation method based on the time-area concept. Various methods to calculate the instantaneous area requirements and the time-area requirements, including continuous formulation and discrete formulation, are compared.

While most of the previous research is focused on comparing multiple modes of transport to transport people, this paper focuses on transporting parcels and evaluates only a single mode of transport. The effect that seasonal and weekly changes and operating strategy changes have on the time-area requirement is analysed based on a real trip dataset of a last mile delivery company in London, UK. The time-area requirements per parcel largely vary between trips. The number of parcels per trip is the only key performance indicator that has a strong correlation with the time-area requirements per parcel. Additionally, the changes in the policy and operating strategy (i.e., parcel locker, second driver, reserved parking spots) have the largest effect, if the number of parcels per delivery trip is increased as well. Overall, it is key for delivery companies to use the smallest possible vehicle that can fit as many parcels per tour as possible.

Author Contributions: Conceptualization, M.S.; Data curation, M.S.; Formal analysis, M.S.; Investigation, M.S.; Methodology, M.S.; Resources, A.W.; Software, M.S.; Supervision, C.H. and A.W.; Validation, M.S., C.H. and A.W.; Visualization, M.S.; Writing—original draft, M.S.; Writing—review and editing, M.S., C.H. and A.W. All authors have read and agreed to the published version of the manuscript. 
Funding: The authors gratefully acknowledge the financial support of the Engineering and Physical Sciences Research Council (EPSRC) Centre for Doctoral Training in Embedded Intelligence under grant reference EP/L014998/1 and Ford Motor company for their support and input to this research.

Acknowledgments: Map data copyrighted OpenStreetMap contributors and available from https://www.openst reetmap.org. Parcel delivery data provided under the Open Government Licence v3.0 maintained by Greater London Authority online available on: https://data.london.gov.uk/dataset/key-performance-indicators-of-demon strator-freight-delivery-performancewith-electric-vans-in-central-london.

Conflicts of Interest: The funders had no role in the design of the study; in the collection, analyses, or interpretation of data; in the writing of the manuscript, or in the decision to publish the results.

\section{References}

1. Sapena, M.; Ruiz, L.A. Analysis of land use/land cover spatio-temporal metrics and population dynamics for urban growth characterization. Comput. Environ. Urban Syst. 2019, 73, 27-39. [CrossRef]

2. Zitti, M.; Ferrara, C.; Perini, L.; Carlucci, M.; Salvati, L. Long-Term Urban Growth and Land Use Efficiency in Southern Europe: Implications for Sustainable Land Management. Sustainability 2015, 7, 3359-3385. [CrossRef]

3. Bruun, E.C. Calculation and Evaluation of The Time-Area Parameter for Different Transportation Modes; University of Pennsylvania, ProQuest Dissertations Publishing: Philadelphia, PA, USA, 1992.

4. Harvey, E.; Cardwell, R.C.; McDonald, G.W.; Van Delden, H.; VanHout, R.; Kim, J.-H.; Smith, N.J.; Forgie, V.E.; Belt, M.V.D. Developing integrated models by coupling together existing models; land use, economics, demographics and transport in Wellington, New Zealand. Comput. Environ. Urban Syst. 2019, 74, $100-113$. [CrossRef]

5. Schnieder, M.; West, A.A. Comparison of Time-Area Requirements of Parcel Lockers vs. Home Delivery: A Cyber-Physical System of Last Mile Delivery; Institute of Electrical and Electronics Engineers (IEEE): Piscataway, NJ, USA, 2020; pp. 298-303.

6. Bruun, E.C.; Vuchic, V.R. Time-area concept: Development, meaning, and applications. Transp. Res. Rec. 1995, 1499, 95-104.

7. Brunner, H.; Hirz, M.; Hirschberg, W.; Fallast, K. Evaluation of various means of transport for urban areas. Energy Sustain. Soc. 2018, 8, 9. [CrossRef]

8. Shin, Y.E.; Vuchic, V.R.; Bruun, E.C. Land Consumption Impacts of a Transportation System on a City. Transp. Res. Rec. J. Transp. Res. Board 2009, 2110, 69-77. [CrossRef]

9. Gartner, N.H.; Carroll, J.M.; Rathi, A. Revised Monograph on Traffic Flow Theory; TRB Special Report; US Department of Transportation: Washington, DC, USA, 1992; p. 165.

10. Litman, T. Transportation Land Valuation Evaluating Policies and Practices that Affect the Amount of Land Devoted to Transportation Facilities; Report; University of Oregon: Portland, OR, USA, 2005.

11. Tranter, M.; Robineau, D.; Goodman, G. National Travel Survey: England 2014; Department for Transport, Office for National Statistics: London, UK, 2015.

12. Manville, M.; Shoup, D. Parking, People, and Cities. J. Urban Plan. Dev. 2005, 131, 233-245. [CrossRef]

13. Shoup, D.C. The trouble with minimum parking requirements. Transp. Res. Part A Policy Pr. 1999, 33, 549-574. [CrossRef]

14. Vlahogianni, E.; Kepaptsoglou, K.; Tsetsos, V.; Karlaftis, M.G. A Real-Time Parking Prediction System for Smart Cities. J. Intell. Transp. Syst. 2015, 20, 192-204. [CrossRef]

15. Davis, A.Y.; Pijanowski, B.C.; Robinson, K.; Engel, B. The environmental and economic costs of sprawling parking lots in the United States. Land Use Policy 2010, 27, 255-261. [CrossRef]

16. Davis, A.Y.; Pijanowski, B.C.; Robinson, K.D.; Kidwell, P.B. Estimating parking lot footprints in the Upper Great Lakes Region of the USA. Landsc. Urban Plan. 2010, 96, 68-77. [CrossRef]

17. TG Road Safety. Safe Distance between Vehicles. Available online: https://www.cedr.eu/download/Publication s/2010/e_Distance_between_vehicles.pdf (accessed on 8 May 2020).

18. Allen, J.; Piecyk, M.; Piotrowska, M.; McLeod, F.; Cherrett, T.; Ghali, K.; Nguyen, T.; Bektas, T.; Bates, O.; Friday, A.; et al. Understanding the impact of e-commerce on last-mile light goods vehicle activity in urban areas: The case of London. Transp. Res. Part D Transp. Environ. 2018, 61, 325-338. [CrossRef]

19. Department for Transport Communities and Local Government. Manual for Streets; Thomas Telford Ltd.: London, UK, 2007. 
20. Purdy, E.R. Transportation Research Board. In Encyclopedia of Transportation: Social Science and Policy; Sage: Thousand Oaks, CA, USA, 2014.

21. Greibe, P.; Buch, T.S. Capacity and Behaviour on One-way Cycle Tracks of Different Widths. Transp. Res. Procedia 2016, 15, 122-136. [CrossRef]

22. Department for Transport. Cycle Infrastructure Design Local Transport Note 2/08; TSO: London, UK, 2008.

23. Schweizerische Post Factsheet Starship Delivery Robot. Available online: https://www.post.ch/-/media/post /ueber-uns/medienmitteilungen/2017/factsheet-lieferroboter.pdf?la=en (accessed on 5 May 2020).

24. Greater London Authority (GLA). Key Performance Indicators of Freight Delivery Performance with Electric Vans in Central London-London Datastore. 2017. Available online: https://data.london.gov.uk/dataset/key-p erformance-indicators-of-demonstrator-freight-delivery-performance-with-electric-vans-in-central-london (accessed on 18 February 2019).

25. Comi, A.; Schiraldi, M.M.; Buttarazzi, B. Smart urban freight transport: Tools for planning and optimising delivery operations. Simul. Model. Pr. Theory 2018, 88, 48-61. [CrossRef]

26. Roca-Riu, M.; Cao, J.; Dakic, I.; Menendez, M. Designing Dynamic Delivery Parking Spots in Urban Areas to Reduce Traffic Disruptions. J. Adv. Transp. 2017, 2017, 6296720. [CrossRef]

Publisher's Note: MDPI stays neutral with regard to jurisdictional claims in published maps and institutional affiliations.

(C) 2020 by the authors. Licensee MDPI, Basel, Switzerland. This article is an open access article distributed under the terms and conditions of the Creative Commons Attribution (CC BY) license (http://creativecommons.org/licenses/by/4.0/). 